\title{
Development of Solar PV Charge Controller System for Rural Application
}

\author{
Punit Ratnani \\ Dept. of Electrical Engineering \\ NMIMS, India \\ Punit.Ratnani@gmail.com
}

\author{
Kashyap Joshi \\ Dept. of Electronics and Telecommunication \\ NMIMS, India
}

\begin{abstract}
In recent year many intelligent techniques and approaches have been introduced in photovoltaic $(\mathrm{PV})$ system for the utilisation of free harvest renewable energy. The modern day power system is undergoing rapid and dynamic metamorphosis from the legacy system, in the direction of an intelligent power system. The use of renewable energy resources as rural electrification at the distribution level is on the rise alongside advances in the efficiency of associated technologies and automation of the power sector. This paper presents a cost effective solar charge controller (SCC) using programmable intelligent controller (PIC) to control and coordinate the functions properly. The source code for the PIC microcontroller will be written in $\mathrm{C}$ to obtain accurate and efficient disconnecting or reconnecting action automatically. Accordingly, battery can be disconnected from solar cell when overcharging and reconnected while under discharging. The proposed charge controller is equipped with Liquid Crystal Display (LCD) to display the battery charging status and amount of current flown from solar cell to load via microcontroller. The Details of design for the construction of SCC using crystal oscillator, optocoupler, Dusk-Down sensor and an In-build digital voltmeter, are presented. The construction, operation and experimental result of our proposed smart solar charge controller indicates that it is more cost effective, reliable and functions properly.
\end{abstract}

Keywords-Solar Charge Controller (SSC), programmable intelligent controller (PIC), Dusk-Down sensor, cost effective and reliable.

\section{INTRODUCTION}

Power is the life blood of a developing economy. India is currently in a state of burgeoning economic development. Nearly $70 \%$ of India's population lives in villages and agricultural is the main support for their livelihood. It is, therefore, ironical that India's rural population shares a much larger burden of poverty as well as energy poverty. Eradicating energy poverty requires that adequate infrastructure is put in place so that power can reach the corners of the country. Moreover, this power must be clean enough to be environmentally acceptable, affordable by the people and also feasible to implement. [1]

In India, where in summer and for most of the seasons there is load-shedding of around 12-14 hours in rural areas, this severally affects the crops and therefore to the agriculture business, which is the main occupation of most of the People [9]. Therefore if there is some alternative to the conventional source of electricity, there can be a reduction in the loss of crops and inconvenience can be minimized. This situation inspires us to go for renewable sources for energy generation. As India is a tropical country, we have ample amount of solar radiations we can go for energy generation from it.
With the world running out of non-renewable fuel sources, researchers have been trying all squares out to find the best renewable source to power the world once the reserves are over. What they have found out is good but they still have to make it the best. When we talk about the sources which have the potential to power the world, wind and sun are the foremost options that strike the mind; however, still we have not been able to develop techniques that completely exploit these sources of unlimited energy. Still, we are in a position to find some techniques that have changed the expensive and non-efficient face of solar power to something which has the potential of improvement.

The cost to install and service the distribution lines is considerably high for remote areas. Also, there will be a substantial increase in transmission line losses in addition to poor power supply reliability. In most of the remote and nonelectrified sites, extension of utility grid lines experiences high capital investment, high lead time, low load factor, poor voltage regulation and frequent power supply interruptions. Hence, a convenient, cost-effective and reliable power supply is an essential factor in the development of any rural area. With reference to the present conditions, solar energy can play a vital role to optimize such problem. So to be with our current focus of renewable energy we have selected solar charge controller and tried to add various functions in order to make it as a effective solution for the problem faced by solar PV systems in rural electrification application [8].

A charge controller is one of functional and reliable major components in PV systems. A good, solid and reliable PV charge controller is a key component of any PV battery charging system to achieve low cost and the benefit that user can get from it. The main function of a charge controller in a $\mathrm{PV}$ system is to regulate the voltage and current from PV solar panels into a rechargeable battery. The minimum function of a PV charge controller is to disconnect the array when the battery is fully charged and keep the battery fully charged without damage. A charge controller is important to prevent battery overcharging, excessive discharging, reverse current flow at night and to protect the life of the batteries in a PV system. A power electronics circuit is used in a PV charge controller to get highest efficiency, availability and reliability.

\section{THEORETICAL BACKGROUND}

\section{A. Problem Formulation:}

As the part of study, we have calculated the basic load requirement of village which varies from 2-4 fluorescent lamps and fans of lower watt rating. Their main requirement of load is during night time; so, by storing the ambient amount of solar energy available during day-hours, estimated load requirements can be easily full-filled. Various 
government incentives and NGO's have provided a hand of support in this regard for the development of these people by providing a solar PV system (with battery, panel, and inverter) but later on it is found that the battery used in the system faces the problem of overcharging and deep discharging due to the lack of control in the system. So, the life of batteries reduces drastically leading to the increasing operating costs.

People living below poverty line cannot afford the system with such a high operating cost because of frequent replacement of new battery after every 1-2 years. In order to cope up with this problem it is necessary to design and develop a device which can easily control the charge flowing from solar panel to battery. By having optimum control on battery charging process, over-charging and deep discharging of battery can be avoided and thus making the overall system reliable and effective.

\section{B. Renewable Energy Sources:}

The estimated potential of various Renewable Energy sources in India by IREDA is shown in Table-I.

The Govt. of India has planned to electrify 18,000 villages by the end of year 2012 through renewable energy systems especially by solar PV systems [10]. This offers tremendous growth potential for Indian solar PV industry. The Govt. of India had a target of achieving $150 \mathrm{MW}$ installed capacity in year 2007[10].

TABLE I. RENEWABLE ENERGY POTENTIAL IN INDIA [5]

\begin{tabular}{|c|c|c|}
\hline Sr. No & Source & Potential \\
\hline 01 & Solar & 20MW/sq.km \\
\hline 02 & Wind & $20,000 \mathrm{MW}$ \\
\hline 03 & Small Hydro & $10,000 \mathrm{MW}$ \\
\hline 04 & Ocean Thermal & $50,000 \mathrm{MW}$ \\
\hline 05 & Tidal & $10,000 \mathrm{MW}$ \\
\hline 06 & Biogas & 12 Million Plants \\
\hline 07 & Biogas based Cogeneration & $3500 \mathrm{MW}$ \\
\hline 08 & MSW & $1000 \mathrm{MW}$ \\
\hline
\end{tabular}

C. Basic Structure of the SCC System:

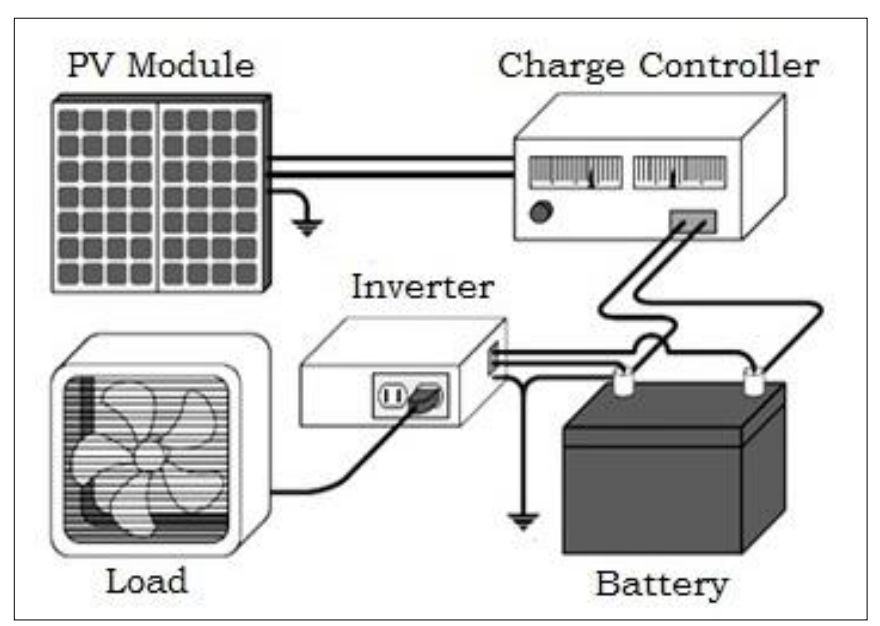

Fig. 1. Proposed Solar PV system
A Solar charge controller (SCC) is a device that controls the flow of charge from a battery to load or from solar panel to battery through a micro-controller So, we can prevent over charging and fastest charging and discharging, also the blocking of the reverse charge also, maintaining the proper use of natural energy.

Battery is an important element to set up a solar panel power system. An electrical battery is one or more electrochemical cells that convert stored chemical energy into electrical energy. For the charging and discharging facilities the secondary batteries are exceedingly used for the solar panel power system. The available capacity of a battery depends upon the rate at which it is discharged. If a battery is discharged at a relatively high rate, the available capacity will be lower than expected. Battery life can be extended by storing charge of the batteries, as in controlling the cover charge of batteries which slows the chemical reactions in the battery. Such storage can extend the life of these types of batteries by about $5 \%$. To reach their maximum voltage, batteries must be stopped to store of charge. As a result, due to these drawbacks and lifespan improvement process of these types of batteries like lead-acid batteries if we use SCC properly then lifespan of batteries can be extended. Basically here it's controlled that battery charging rate is kept normal, not fast or slow. The discharge limit will not go under the $50 \%$. The microcontroller can sense according the program that when it's needed to give charge and when at nearly full charged it's needed to cut off from the solar panel. For further operation this proposed SCC can control the movement of the load according the charge and discharge of the battery.

The proposed SCC consists of a voltage regulator, a microcontroller and a crystal oscillator. Depending upon voltage level at battery terminal, which is set by the microcontroller, it controls the charging of battery from solar panel and hence improves the operational life of a battery. It can also prevent the battery from complete discharging by disconnecting the load from the battery when the voltage level reaches to a critical value set by the micro-controller. It is our purpose to propose a reliable and effective SCC which improves the existing solar charges controller devices and the battery life of the solar system. This SCC can fulfill nearly all requirements which are needed for proper operation of solar energy system and the charging or discharging of battery can be controlled accurately.

\section{SYSTEM STRUCTURE \& ANALYSIS}

Solar-powered lighting systems are already available in rural as well as urban areas. These include solar lanterns, solar home lighting systems, solar streetlights, solar garden lights and solar power packs. All of them consist of four components: solar photovoltaic module, rechargeable battery, solar charge controller and load. The proposed solar charge controller system can be used with any of the above application.

Basically, there are two methods of controlling the charging current known as series regulation and parallel (shunt) regulation. A series regulator is inserted between the solar panel and the battery. The series type of regulation 'wastes' a lot of energy while charging the battery as the control circuitry is always active and series regulator requires the input voltage to be 3-4 volts higher than the output voltage. The current and voltage output of a solar panel is 
governed by the angle of incidence of light, which keeps varying.

Parallel regulation is preferred in solar field. In parallel regulation, the control circuitry allows the charging current (even in $\mathrm{mA}$ ) to flow into the battery and stop charging once the battery is fully charged. At this stage, the charging current is wasted by converting into heat (current is passed through low-value, high-wattage resistor); this part of the regulation dissipates a lot of heat. In this design, we have used parallel regulation technique but instead of wasting the charging current as heat, we have made it pulsed and applied to the battery to keep the battery topped-up. After power-on, the microcontroller reads the battery voltage with the help of the ADC and displays the values on the LCD. It monitors the input signal from the dusk-to-dawn sensor and activates the load or charging relay accordingly. The digital voltmeter works up to $20 \mathrm{~V}$. As $\mathrm{V}_{\text {ref }}$ of the ADC is connected to $\mathrm{V}_{\mathrm{CC}}$ $(5 \mathrm{~V})$, the input voltage to the ADC cannot exceed $+5 \mathrm{~V}$. A potential divider is used with the ADC using resistors three resistors to scale down the voltage from $0 \mathrm{~V}-20 \mathrm{~V}$ to $0 \mathrm{~V}-05 \mathrm{~V}$. The ADC output is multiplied four times and displayed on the LCD as battery voltage.

When the solar panel voltage is present, the dusk-todawn sensor provides a signal to the microcontroller, which then displays 'charging' message on the LCD. During charging, the battery voltage is continuously monitored. When the voltage reaches $14.0 \mathrm{~V}$, the microcontroller interrupts the charging current by energizing the relay, which is connected to MOSFET BS170, and starts a 5-minute timer. During this stage, the LCD shows "battery full." After five minutes, the relay reconnects the panel to the battery. This way, the charging current is pulsed at the intervals of five minutes and the cycle repeats until the panel voltage is present.

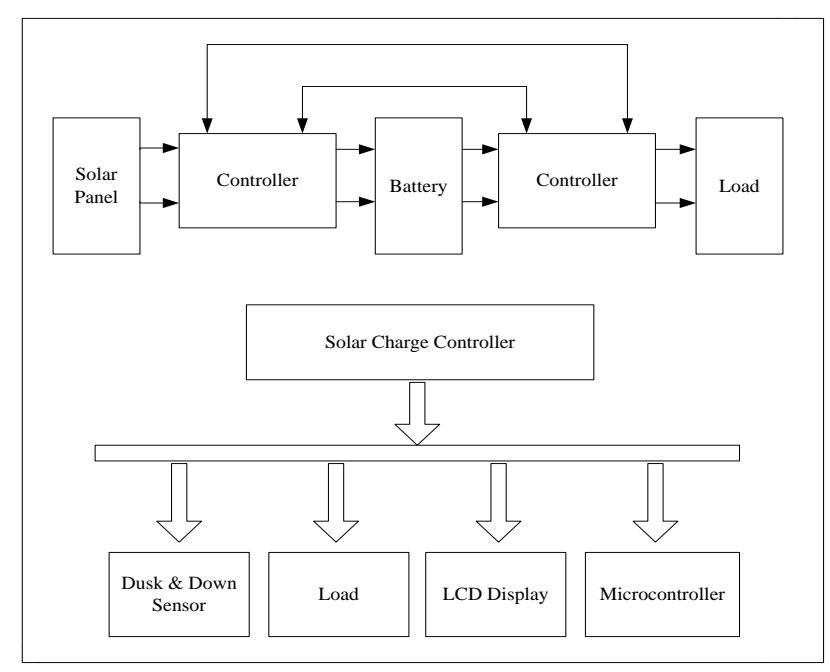

Fig. 2. Functional Block diagram of proposed PV system:

When the panel voltage falls below the zener diode voltage of the dusk-to-dawn sensor, the microcontroller senses this and activates the load by switching on MOSFET via optocoupler and "load on" message is displayed.
In this mode, the microcontroller monitors for low battery. When the battery voltage drops below 10 volts, the microcontroller turns off the load by switching off MOSFET and "battery low-load off" message is displayed. Normally, when the load is switched off, the battery voltage tends to rise back and the load oscillates between 'on' and 'off' states.

To avoid this, the microcontroller employs a hysteresis control by entering into a 'lock' mode during low battery state and comes out of the lock mode when the dusk-to-dawn sensor receives the panel voltage (the next morning). During lock mode, the microcontroller keeps converting the ADC value and displays the battery voltage on the LCD.

\section{A. Components Specifications.}

The various components used in the design of this project are described below.

\section{1) Solar Panel.}

PV cells convert sunlight directly into electricity without creating any air or water pollution. PV cells are made of at least two layers of semi- conductor material. One layer has a positive charge, the other negative. When light enters the cell, some of the photons from the light are absorbed by the semiconductor atoms, freeing electrons from the cell's negative layer to flow through an external circuit and back into the positive layer. This flow of electrons produces electric current. To increase their utility, dozens of individual PV cells are interconnected together in a sealed, weatherproof package called a module. So when two modules are wired together in series, their voltage is doubled while the current stays constant. For designing this SCC we have used solar panel module of $85 \mathrm{Wp}$ and its data sheet is given in Table-II.

TABLE II. DATASHEET OF 85 WP MODULE. [6]

\begin{tabular}{|l|c|}
\hline \multicolumn{1}{|c|}{ Module Type } & BLD85-36M (Mono crystalline) \\
\hline Peak power & $85 \mathrm{Wp}$ \\
\hline Maximum Power Voltage & $18.05 \mathrm{~V}$ \\
\hline Maximum Power Current & $4.71 \mathrm{~A}$ \\
\hline Open circuit Voltage & $21.94 \mathrm{~V}$ \\
\hline Short Circuit Current & $5.29 \mathrm{~A}$ \\
\hline Cell Efficiency & $16 \%$ \\
\hline Module Efficiency & $12.87 \%$ \\
\hline Area of Panel & $1200 \times 550 \times 35 \mathrm{~mm}$ \\
\hline
\end{tabular}

When two modules are wired in parallel, their current is doubled while the voltage stays constant. To achieve the Desired voltage and current modules are wired in series or parallel To increase their utility, dozens of individual PV cells are interconnected together in a sealed, weatherproof package called a module. When two modules are wired together in series, their voltage is doubled while the current stays constant. When two modules are wired in parallel, their current is doubled while the voltage stays constant 


\section{2) Battery Bank.}

PV panels will produce electricity whenever the sun shines on them. Our system is off-grid, so we will need a battery bank, a group of batteries wired together to store energy so we can have electricity at night or on cloudy days. For off-grid systems, battery banks are typically sized to keep household electricity running for one to three cloudy days. Grid inter tied systems also can include battery banks to provide emergency backup power during blackouts, perfect for keeping critical electric loads operating until grid power is restored. The ampere-hr rating of battery can range from 5-Ahr to 100-Ahr.

\section{3) Micro-Controller.}

Microcontroller is the heart of the circuit. It is a lowvoltage, high-performance, 8-bit microcontroller that features $2 \mathrm{~kb}$ of Flash, 128 bytes of RAM, 15 input or output (I/O) lines, two 16-bit timers or counters, a five-vector two-level interrupt architecture, a full-duplex serial port, a precision analogue comparator, on-chip oscillator and clock circuitry. A $12 \mathrm{MHz}$ crystal is used for providing the basic clock frequency.

\section{4) Serial $A D C$.}

The microcontroller monitors the battery voltage with the help of an analogue-to-digital converter. The ADC is an 8-bit successive approximation analogue to digital converter with a serial and very low conversion time of typically $32 \mu$ s. The differential analogue voltage input allows increase of the common mode rejection (CMR) and offsetting of the analogue zero input voltage. In addition, the voltage reference input can be adjusted to allow encoding of any smaller analogue voltage span to the full eight bits of resolution. It is available in an 8-pin PDIP package and can be interfaced to the microcontroller with only three wires.

\section{5) LCD Module.}

The system status and battery voltage are displayed on an LCD. The backlight feature of the LCD makes it readable even in low light conditions. The LCD is used here in 4-bit mode to save the microcontroller's port pins. Usually the 8bit mode of interfacing with a microcontroller requires eleven pins, but in 4 bit mode the LCD can be interfaced to the microcontroller.

\section{6) Dusk to Dawn Sensor.}

Normally, in a solar-photovoltaic based installation, for example, solar home lighting system, solar lantern or solar streetlight, the load (the light) is switched on at dusk (evening) and switched off at dawn (morning). During daytime, the load is disconnected from the battery and the battery is recharged with current from the solar panel. The microcontroller needs to know the presence of the solar panel voltage to decide whether the load is to be connected to or disconnected from the battery, or whether the battery should be in charging mode or discharging mode.

\section{B. Working Flow Chart Diagram and Experimental result of SCC.[4]}

In the solar-powered lighting system, the solar charge controller plays an important role as the system's overall success depends mainly on it. It is considered as an indispensable link between the solar panel, battery and load. The SCC system follows given flow chart to accomplish its desired features.

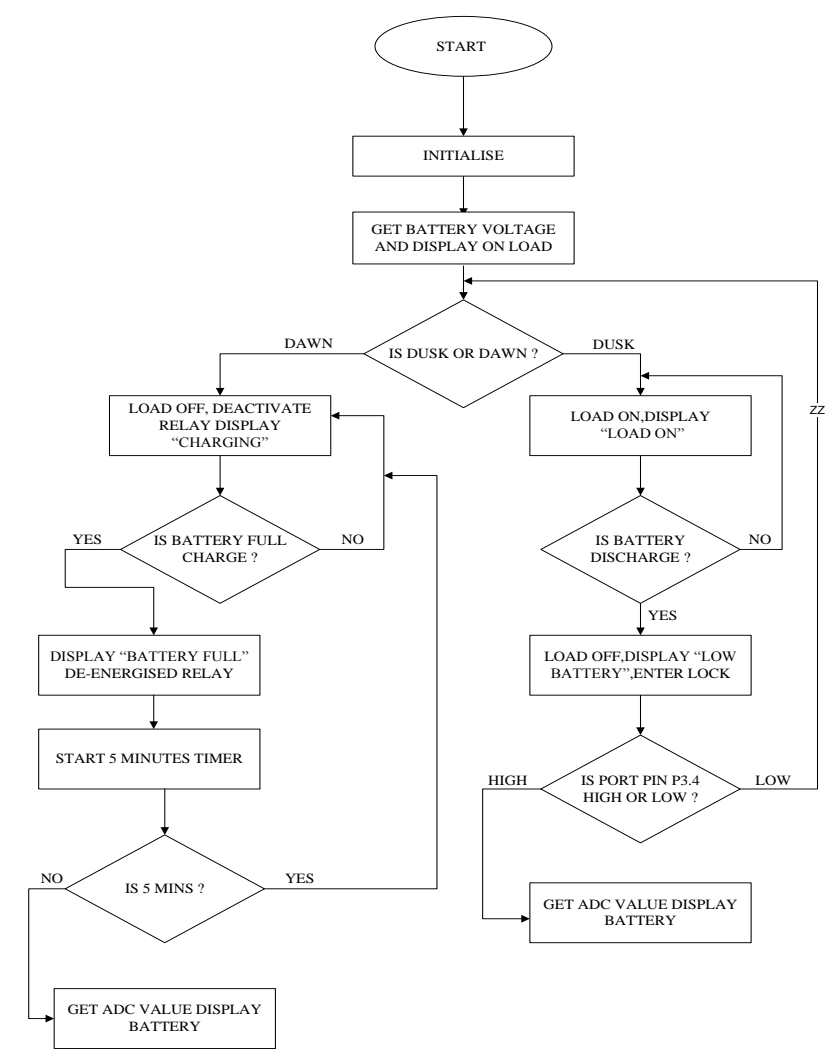

Fig. 3. Flow chart of SCC [4].

After constructing a prototype model of solar charge controller, we have tested it under various conditions and we obtained the result as desired. Now in order to make it more reliable we are planning to add some other functions so, further testing of this prototype model is going on. The microcontroller-based solar charge controller described here has the following features.

- Automatic dusk to dawn operation of the load.

- Built-in digital voltmeter (0 Volt-20 Volt range).

- Parallel or shunt-type regulation.

- Overcharge protection.

- System status display on LCD.

- Deep-discharge protection.

- Low battery lock.

- Charging current changes to 'pulse' at full charge.

- Low current consumption.

- Highly efficient design based on microcontroller.

- Conclusion

Renewable energy is inexhaustible, clean and they can be used in a decentralised way, originating from the most part in the form of the sun's radiant energy. This energy is ubiquitous, long-lived, essentially free of carbon emission, and have the potentiality to contribute significantly to mounting the energy needs of the globe.

Solar energy technologies have great potential to benefit our nation. They can diversify our energy supply, reduce our dependence on imported fuels, and improves the quality of the air we breathe, offset greenhouse gas emissions, and 
stimulate our economy by creating jobs in the manufacturing and installation of solar energy systems. The solar radiations are available sufficiently over the country. So India must take initiative to adopt the Grid free solar PV system to fulfillment of present demand-supply gap [1].

The proposed solar PV system with charge controller design can prove its effectiveness and reliability in rural application like solar lantern charging stations in villages and municipal street lighting systems. The programmable controller and LCD display used in this system not only provides user-friendly environment while operating but also provides automatic control in every operation.

\section{REFERENCES}

[1] Punit Ratnani et al, "Design and Development of Fast Charging for Lead Acid Battery", Global Conference for advancement in Technology 2019, Published on IEEE Xplore, https://ieeexplore.ieee.org/document/8978435/

[2] Aditya Kasar, Punit Ratnani, "Design of 20kWp solar PV-Wind hybrid system at NMIMS Navi Mumbai- A case study" International Journal of Modern Engineering Research (IJMER) June 2018.

[3] Tarujyoti Buragohain, "Renewable Energy and Rural Environment in India: Challenges Ahead,"2012 International Conference on Environment, Energy and Biotechnology IPCBEE vol.33 (2012), IACSIT Press, Singapore.

[4] Md. Ashiquzzaman, Nadia Afroze, Md. JabedHossain, Umama Zobayer, and Md. Mottaleb Hossain, "Cost Effective Solar Charge
Controller Using Microcontroller," proc. Canadian Journal on Electrical and Electronics Engineering, Vol. 2, No. 12, December 2011

[5] Gazi Mohammad Sharif, S. M. Mohaiminul Islam, Khosru Mohammad Salim "Design \& Construction of Microcontroller Based maximum power point PWM Charge Controller for Photovoltaic Application"

[6] A Project manual on "Microcontroller-Based Solar Charger"

[7] Dr. Vadirajacharya, Dr. P.K.Katti,'Rural electrification through solar and wind hybrid system: a self sustained grid free electric power source", $2^{\text {nd }}$ international conference on Advances in Energy and Engineering, ICAEE2011 ,Bangkok, Thiland. 27-28 Dec 2011.

[8] Severin Borenstein,"The Market Value and Cost of Solar Photovoltaic Electricity Production," Center for the Study of Energy Markets (CSEM) Working Paper Series. CSEM is a program of the University of California Energy Institute.

[9] Noor Juwaina Ayuni Bt. Mohd, "Photovoltaic Charge Controller," thesis submitted as partial fulfillment of the requirements for the award of the Masters Degree of Electrical Engineering (Electronics), University of Malaysia.

[10] Snigdha Chakrabarti, Subhendu Chakrabarti, "Rural electrification programme with solar energy in remote region: a case study in an island," Economic Research Unit, Indian Statistical Institute.

[11] S. P. Sukthatme, "solar energy principle of thermal storage", TMH Publications New Delhi 2002, pp 313-314.

[12] Energy Alternatives India.

[13] Meteorological Department of Pune.

\section{APPENDIX}

The Circuit Diagram of the implemented solar charge controller

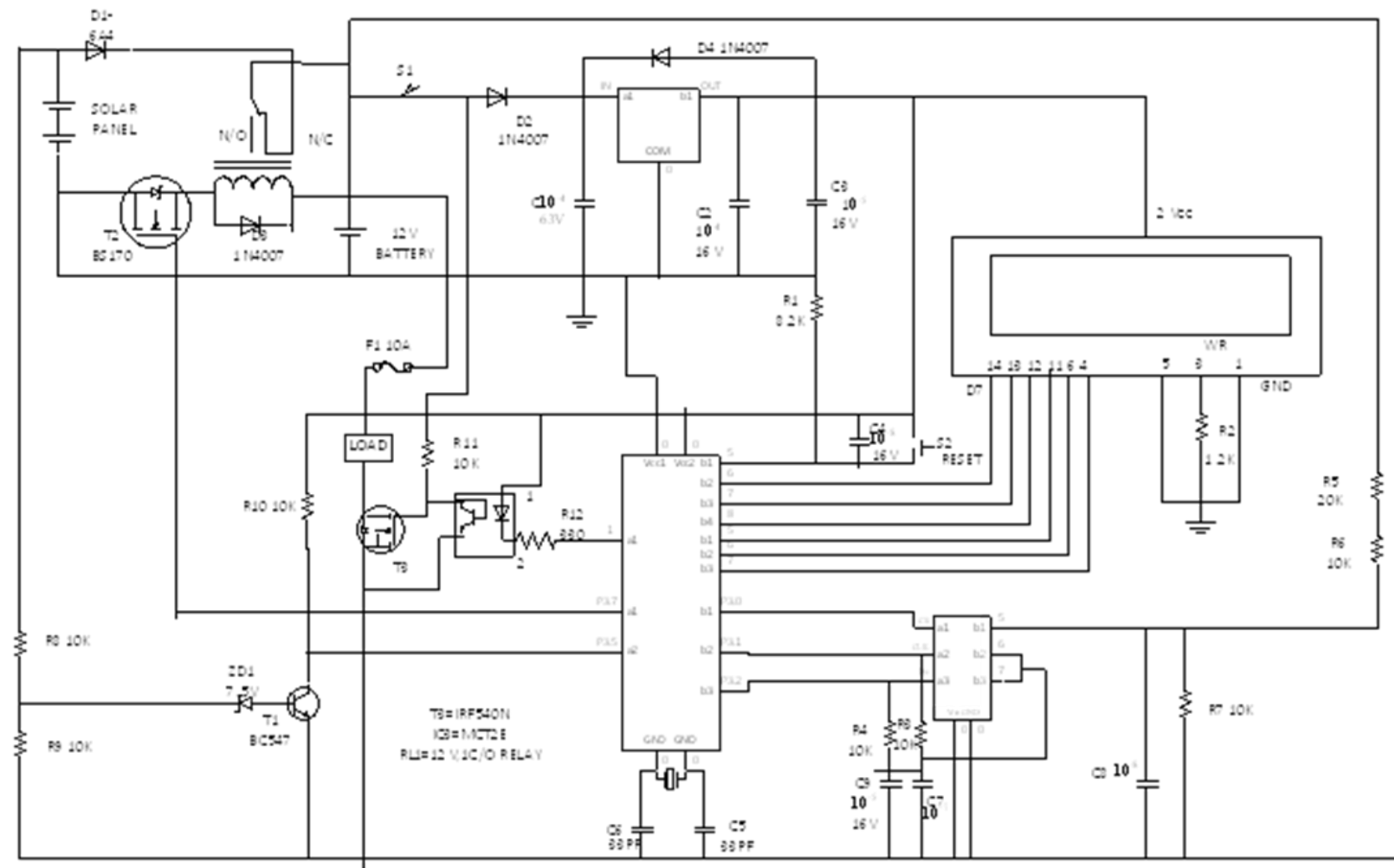

